\title{
Concretos produzidos com resíduos do beneficiamento de ágata: avaliação da resistência à compressão e do consumo de cimento
}

\author{
BETAT $^{\text {I }}$, E.F.; PEREIRA ${ }^{\text {II }}$, F.M.; VERNEY ${ }^{\text {II }}$, J.C.K. de \\ ${ }^{I}$ Mestre em Engenharia pelo Programa de Pós-Graduação em Engenharia: Energia, Ambiente e Materiais, \\ PPGEAM/ULBRA, Av. Farroupilha, no 8001, Prédio 29, sala 203, CEP 92425-900, Canoas, RS \\ e-mail: evertonbetat@pop.com.br \\ ${ }^{\text {II }}$ Professor Doutor do Programa de Pós-Graduação em Engenharia: Energia, Ambiente e Materiais, \\ PPGEAM/ULBRA, Av. Farroupilha, nº 8001, Prédio 29, sala 203, CEP 92425-900, Canoas, RS \\ e-mail: fernanda.pereira@ulbra.br; jcverney@ulbra.br
}

\section{RESUMO}

No Estado do Rio Grande do Sul, os processos produtivos de beneficiamento de pedras semipreciosas, como a ágata, geram resíduos que demandam soluções quanto ao destino do passivo acumulado no processo. A utilização de resíduos e subprodutos industriais na Construção Civil apresenta-se como uma excelente alternativa para diminuição do impacto ambiental e contribuição para o desenvolvimento sustentável. O presente trabalho avalia a influência da utilização do resíduo de ágata como agregado graúdo na resistência à compressão e no consumo de cimento de concretos produzidos com diferentes proporcionamentos e teores de agregado reciclado. Para a produção dos concretos foram utilizados os traços 1:3,5; 1:5,0 e 1:6,5, com três teores de substituição do agregado graúdo natural pelo agregado graúdo reciclado: $25 \%, 50 \%$ e $75 \%$. Com os resultados de resistência à compressão foram obtidos diagramas de dosagem para cada teor de agregado reciclado e determinados os consumos de cimento para concretos com diferentes níveis de resistências. A análise dos resultados permitiu concluir que a utilização do resíduo de ágata em concretos pode ser viável, sendo o teor de 50\% de substituição o que apresentou melhor desempenho.

Palavras-chaves: agregado reciclado de ágata, concreto, consumo de cimento, resistência à compressão.

\section{Concretes produced with waste of agate processing: assessment of compressive strength and cement content}

\section{ABSTRACT}

In the State of Rio Grande do Sul, the productive processes of semiprecious stones beneficiation such as agate produces wastes that demand a solution for the destination of the liabilities accumulated in the process. The use of waste and industrial by-products in the Civil Construction presents an excellent alternative to reduce the environmental impact and contributes for the sustainable development. This paper evaluates the influence of the use of agate waste as coarse aggregate in the compressive strength and the cement content for concrete produced with different mixes and recycled aggregate proportioning. For concrete production the mixes 1:3,5; 1:5,0 and 1:6,5 have been used, each one with three different recycled aggregate content: $25 \%$, $50 \%$ and $75 \%$. From the results of compressive strength test, diagrams for each recycled aggregate and cement content for different levels of compressive strength have been obtained. The analysis of the results showed that the use of agate waste in concrete is viable, and a $50 \%$ of recycled aggregate content presented the best performance.

Keywords: agate waste aggregate, cement content, compressive strength, concrete.

\section{INTRODUÇÃO}

A busca por um melhor relacionamento do homem com o ambiente marcou as duas últimas décadas do século XX e preconiza atualmente uma busca cada vez maior por políticas ambientais mais eficientes que venham a utilizar novas tecnologias e produtos, cujos sistemas produtivos minimizem ao máximo qualquer tipo de impacto ambiental. Contudo, o aumento crescente da população urbana, associado ao crescimento no 
consumo de bens industrializados nos últimos 50 anos, gerou um passivo acumulado de resíduos potencialmente poluidores que podem se apresentar como um problema ambiental passível de intervenção imediata [1].

Processos produtivos como o do beneficiamento da ágata no Estado do Rio Grande do Sul são exemplos de sistemas geradores de resíduos e que atualmente demandam soluções tanto do ponto de vista do gerenciamento do processo quanto da manutenção do passivo de resíduos acumulados. Dos resíduos apresentados pelas indústrias de pedras semipreciosas da cidade de Lajeado, no Estado do Rio Grande do Sul, os provenientes do beneficiamento da ágata são compostos por duas partes distintas, sendo uma formada por fragmentos de rocha com granulometria variada e outra por uma pasta composta por pó da rocha misturado com o óleo diesel do processo de beneficiamento. O resíduo formado pelos fragmentos de rocha tem como destino, por tratar-se de um resíduo inerte, a deposição no pátio da indústria ou o uso em aterros. O resíduo da pasta é armazenado em tambores fechados, conforme determinação do órgão ambiental do Estado (FEPAM - Fundação Estadual de Proteção Ambiental), aguardando um possível destino. Os volumes de resíduos de ágata produzidos mensalmente na região chegam a 25 toneladas por mês de fragmentos de ágata, tendo um passivo acumulado de 10.000 toneladas, e de 5 toneladas por mês de lama de ágata, tendo um passivo acumulado de 2.000 toneladas [2]. Os resíduos provenientes do beneficiamento de ágata apresentam-se como um grande problema do ponto de vista ambiental e, simultaneamente, como uma oportunidade para aproveitamento como agregado na construção civil [3] .

Pesquisas realizadas no início do século XXI pela CIVIL ENGINEERING RESEARCH FOUNDATION []ㅡ apontam a questão ambiental como uma das maiores preocupações dos líderes do setor da construção civil. Tal preocupação deve-se principalmente ao fato de que a construção civil é responsável por consumir entre 15 e 50\% dos recursos naturais extraídos [4]. No Brasil, somente para produção de concreto e argamassas, são consumidos cerca de 220 milhões de toneladas de agregados [ㅍ]. Os agregados, quando facilmente disponíveis, são recursos minerais de relativo baixo custo, o que resulta no fato de que a sua substituição por outros materiais alternativos é quase nula, se analisada sob o ponto de vista econômico.

Apesar do desenvolvimento de técnicas que permitem a utilização de materiais alternativos como agregados para a produção de concreto, e mesmo o fato de que estes agregados possam melhorar suas características e custo, a aceitação de novos materiais dentro do mercado da construção civil e pelos profissionais da área ainda é restrita, impedindo o avanço tecnológico, econômico e ambiental do setor [్].

Rochas para britagem são facilmente encontradas na natureza, sendo consideradas recursos minerais abundantes. Entretanto, fatores como a distância entre a reserva e o ponto de consumo acarretam em custos de transporte, que podem exceder em até $50 \%$ o valor do produto final. Outros fatores, como as áreas de proteção ambiental, que restringem tanto o nível de produção quanto à vida útil das pedreiras em operação e inviabilizam a abertura de novas pedreiras, as leis de zoneamento municipais, restritivas também ao aproveitamento dos recursos existentes, e a própria expansão urbana podem dificultar o acesso aos recursos naturais.

O concreto de cimento Portland, considerado o produto básico da construção civil, consome cerca de $80 \%$ de agregados na sua composição. Por um lado, tem-se o concreto, grande consumidor de agregados e base para o desenvolvimento da construção civil, por outro, tem-se a tendência natural das reservas de produção de agregado em tornarem-se mais escassas, por serem recursos naturais finitos cujo processo de obtenção é cada vez mais discriminado dentro de uma nova consciência ambiental. Deste contraponto conclui-se que a construção civil e o concreto possam vir a serem alternativas indicadas para absorver os resíduos sólidos provenientes dos diversos processos produtivos, na tentativa de tornar esta atividade mais sustentável [6].

Diversas pesquisas já foram realizadas utilizando diferentes tipos de agregados reciclados para produção de concretos, como resíduos de construção e demolição [ㄱ-12]; resíduos de E.V.A. [13]; escória de cobre [6] ; areia de fundição [14]; entre outros, apontando a viabilidade da utilização de agregados reciclados no concreto, conforme o percentual de substituição.

Senthamarai e Manoharan [15], em estudo realizado com descarte de cerâmicas de isoladores elétricos para avaliar o uso do resíduo como agregado graúdo para confecção de concretos, considerando diferentes relações água/cimento, verificaram que a trabalhabilidade dos concretos com resíduos não foi alterada e que os valores de resistência à compressão não diferiram significativamente dos concretos convencionais. Yang et al. [16] estudaram o uso de resíduos de conchas de ostras como agregado miúdo para concretos, em percentuais de substituição que variaram de 5 a $20 \%$, constatando que a trabalhabilidade do concreto diminuiu com o aumento da quantidade de resíduos, mas que não houve decréscimo na resistência à compressão. O uso de plástico tipo PET como agregado para substituição de agregado miúdo na elaboração de concretos foi avaliado por Choi et al. [17] utilizando percentuais de substituição de 25, 50 e 75\%, e três relações água/cimento $(0,45,0,49$ e 0,53$)$. Os autores observaram que a trabalhabilidade do concreto aumentou proporcionalmente ao aumento no uso de agregados de PET, possivelmente devido à menor absorção de água do material e que a resistência à compressão foi menor quando comparada a concretos de 
referência, diminuindo com o aumento no percentual de uso de PET. Em recente estudo MODRO et al. [18] avaliaram a utilização de resíduos de PET em concretos, verificando uma tendência de redução da resistência à compressão do concreto com o aumento do teor de agregado reciclado.

O presente trabalho tem por objetivo avaliar o efeito da substituição de agregado graúdo natural por agregado reciclado, proveniente de fragmentos de rocha resultantes do processo do beneficiamento de ágata, na resistência à compressão e consumo de cimento de concretos com diferentes proporcionamentos.

\section{MATERIAIS E MÉTODOS}

\subsection{Planejamento do experimento}

Para a avaliação da resistência à compressão de concretos com resíduos de ágata como agregado graúdo foram definidas como variáveis independentes o traço do concreto e o teor de substituição de agregado natural por agregado reciclado, conforme apresentado na Tabela 1.

Tabela 1: Variáveis independentes

\begin{tabular}{c|c}
\hline Variáveis independentes & Níveis \\
\hline Traço do concreto & $1: 3,5 ; 1: 5,0$ e $1: 6,5$ \\
Teor de substituição de agregado graúdo natural & $0 \% ; 25 \% ; 50 \%$ e $75 \%$ \\
\hline
\end{tabular}

A Tabela 2 apresenta as combinações de variáveis analisadas, totalizando doze misturas de concreto.

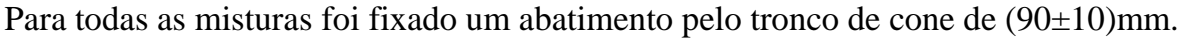

Tabela 2: Misturas analisadas no experimento

\begin{tabular}{l|c|c|c|c}
\hline \multicolumn{2}{c|}{ Sigla/Mistura } & Traço & \% Agregado reciclado & \% Agregado natural \\
\hline \multirow{3}{*}{ CREF } & 1 & $1: 3,5$ & & 100 \\
& 2 & $1: 5,0$ & 0 & \\
& 3 & $1: 6,5$ & & 75 \\
CRA25 & 4 & $1: 3,5$ & & \\
& 5 & $1: 5,0$ & 25 & 50 \\
& 6 & $1: 6,5$ & & \\
CRA50 & 7 & $1: 3,5$ & & \\
& 8 & $1: 5,0$ & 50 & \\
& 9 & $1: 6,5$ & & \\
\hline \multirow{5}{*}{ CRA75 } & 10 & $1: 3,5$ & & \\
& 11 & $1: 5,0$ & & \\
& 12 & $1: 6,5$ & & \\
\hline
\end{tabular}

Para cada mistura foram moldados dois corpos-de-prova, conforme recomenda a NBR 12655 [19], para o ensaio de resistência à compressão aos 28.

\subsection{Materiais utilizados}

\subsubsection{Cimento Portland}

Para a produção dos concretos foi utilizado cimento Portland CP IV-32, proveniente de um mesmo lote de fabricação, por ser o tipo de cimento de maior disponibilidade no varejo no Estado do Rio Grande do Sul. A Tabela 3 apresenta as características químicas e físico-mecânicas do cimento utilizado. 
Tabela 3: Características do cimento utilizado

\begin{tabular}{c|c|lc|c}
\hline \multicolumn{2}{c|}{ Características químicas } & \multicolumn{2}{|c}{ Características físico-mecânicas } \\
\hline $\mathrm{SiO}_{2}$ & 30,82 & Água de consistência normal $(\%)$ & 32,8 \\
$\mathrm{Al}_{2} \mathrm{O}_{3}$ & 10,86 & Superfície específica Blaine $\left(\mathrm{cm}^{2} / \mathrm{g}\right)$ & 4425 \\
$\mathrm{Fe}_{2} \mathrm{O}_{3}$ & 3,78 & Massa específica $\left(\mathrm{kg} / \mathrm{dm}^{3}\right)$ & 2,72 \\
$\mathrm{CaO}$ & 41,29 & Finura \#200 (\%) & 0,45 \\
$\mathrm{MgO}$ & 3,32 & Finura \#325 (\%) & 2,74 \\
Equivalente & 1,05 & Tempos de pega & Início (h:min) & $3: 10$ \\
alcalino & & & Fim (h:min) & $6: 05$ \\
$\mathrm{CO}_{2}$ & 2,95 & Expansibilidade a frio (mm) & 0,0 \\
$\mathrm{SO}_{3}$ & 2,12 & & 3 dias & 16,5 \\
$\mathrm{PF}$ & 2,30 & Resistência à & 7 dias & 23,9 \\
$\mathrm{RI}$ & 40,83 & & & \\
\hline
\end{tabular}

\subsubsection{Agregados}

Como agregado miúdo foi utilizado areia natural quartzosa, proveniente do leito do Rio Jacuí, cujas características são apresentadas na Tabela 4. A curva granulométrica da areia utilizada é apresentada na Figura 1. Como agregado graúdo natural foi utilizada brita de origem basáltica, cujas características estão apresentadas nas Tabelas 4 e 5. A curva granulométrica da brita basáltica é apresentada na Figura 3.

Tabela 4: Características físicas dos agregados

\begin{tabular}{|c|c|c|c|c|c|c|}
\hline \multicolumn{7}{|c|}{ Composição granulométrica [20] } \\
\hline \multirow[b]{2}{*}{ Peneiras } & \multicolumn{3}{|c|}{ \% Retida } & \multicolumn{3}{|c|}{ \% Acumulada } \\
\hline & Miúdo & $\begin{array}{l}\text { Graúdo } \\
\text { natural }\end{array}$ & $\begin{array}{c}\text { Graúdo } \\
\text { reciclado }\end{array}$ & Miúdo & $\begin{array}{l}\text { Graúdo } \\
\text { natural }\end{array}$ & $\begin{array}{c}\text { Graúdo } \\
\text { reciclado }\end{array}$ \\
\hline $19 \mathrm{~mm}$ & - & 1 & 5 & - & 1 & 5 \\
\hline $12,5 \mathrm{~mm}$ & - & 42 & 58 & - & 43 & 63 \\
\hline $9,5 \mathrm{~mm}$ & - & 26 & 23 & - & 69 & 86 \\
\hline $6,3 \mathrm{~mm}$ & - & 24 & 9 & - & 93 & 95 \\
\hline $4,75 \mathrm{~mm}$ & 1 & 4 & 3 & 1 & 97 & 98 \\
\hline $2,36 \mathrm{~mm}$ & 3 & 2 & 2 & 4 & 99 & 100 \\
\hline $1,18 \mathrm{~mm}$ & 3 & - & - & 7 & 99 & 100 \\
\hline $600 \mu \mathrm{m}$ & 19 & - & - & 26 & 99 & 100 \\
\hline $300 \mu \mathrm{m}$ & 60 & - & - & 86 & 99 & 100 \\
\hline $150 \mu \mathrm{m}$ & 13 & - & - & 99 & 99 & 100 \\
\hline Fundo & 1 & 1 & 0 & 100 & 100 & 100 \\
\hline TOTAL & 100 & 100 & 100 & 208 & 662 & 689 \\
\hline \multicolumn{4}{|c|}{ Módulo de finura [20] } & 2,08 & 6,62 & 6,89 \\
\hline \multicolumn{4}{|c|}{ Dimensão máxima característica (mm) [20] } & 2,36 & 19 & 19 \\
\hline \multicolumn{4}{|c|}{ Massa específica [21] } & 2,63 & 2,93 & 2,62 \\
\hline
\end{tabular}




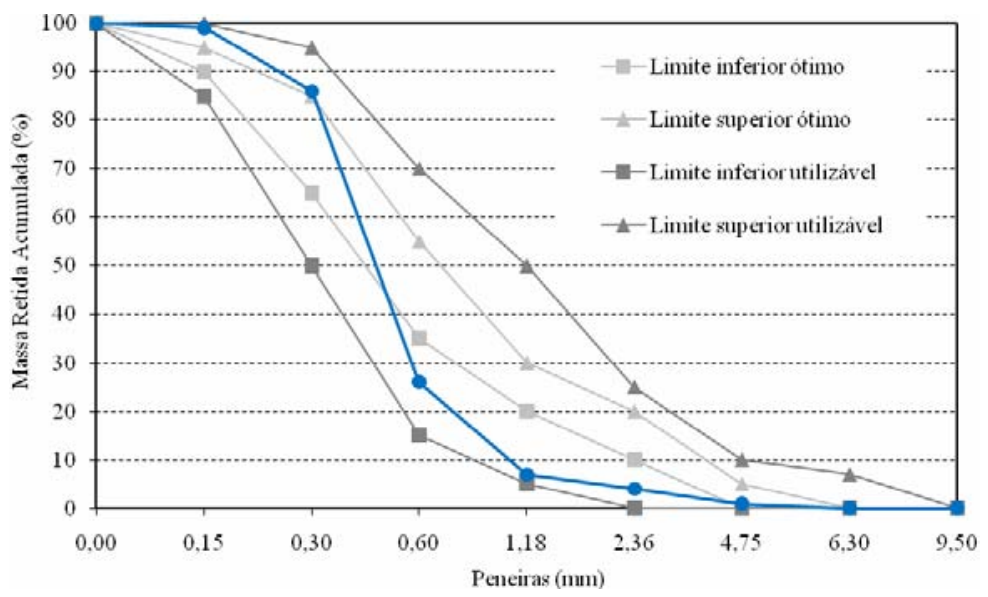

Figura 1: Curva granulométrica do agregado miúdo e limites da NBR 7211 [22].

Tabela 5: Índice de forma e características morfológicas dos agregados graúdos

\begin{tabular}{c|c|c}
\hline Agregado & Graúdo natural & Graúdo reciclado \\
\hline $\begin{array}{c}\text { Índice de forma [23] } \\
\text { Classificação quanto à relação das } \\
\text { dimensões [23] }\end{array}$ & 2,80 & 3,02 \\
$\begin{array}{c}\text { Classificação quanto às arestas e cantos } \\
\text { [23] }\end{array}$ & $\begin{array}{c}\text { Anguloso e } \\
\text { Arredondado }\end{array}$ & Lamelar \\
Classificação quanto às faces [23] & Conchoidal & Conchoidal \\
\hline
\end{tabular}

O agregado reciclado foi obtido a partir do beneficiamento dos resíduos gerados no processamento de ágata do município de Lajeado/RS. Os resíduos foram coletados na área de depósito de uma empresa beneficiadora de ágata, apresentando-se sob a forma de fragmentos de rocha de tamanhos e formatos variados (Figura 2a). Os resíduos foram britados em britador de mandíbulas, a fim de diminuir o tamanho dos fragmentos, permitindo a obtenção de agregados utilizáveis em concretos de cimento Portland. O material obtido no britador de mandíbulas foi então peneirado, tendo sido utilizado o material passante na peneira com malha $25 \mathrm{~mm}$ e retido na peneira com malha $4,75 \mathrm{~mm}$ (Figura $2 \mathrm{~b}$ ).

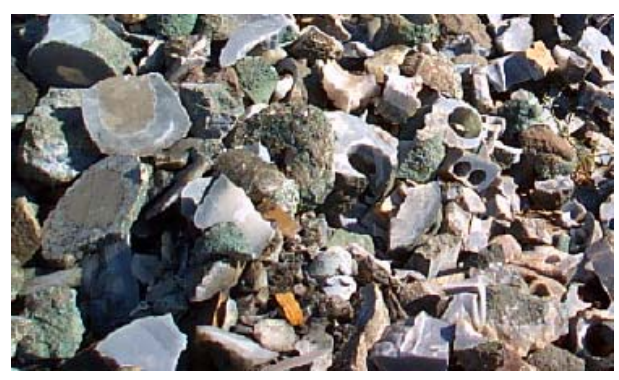

(a)

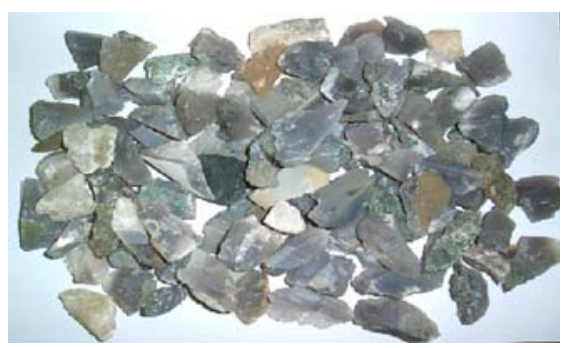

(b)

Figura 2: Resíduos de ágata (a) antes e (b) após o beneficiamento.

As características físicas do agregado reciclado, determinadas após o beneficiamento do resíduo, são apresentadas nas Tabelas 4 e 5 . A curva granulométrica do agregado reciclado apresenta-se na Figura 3. 


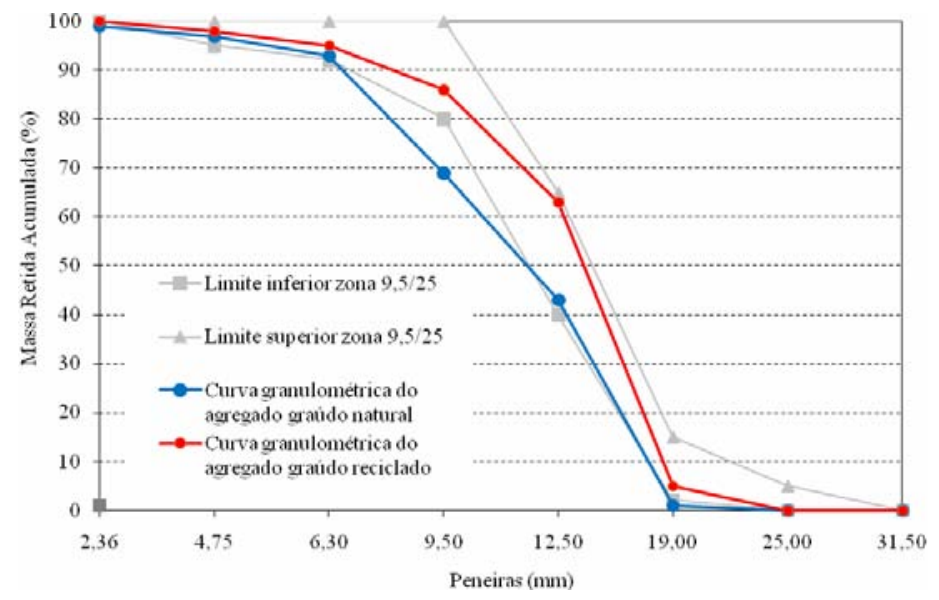

Figura 3: Curvas granulométricas dos agregados graúdos e limites da NBR 7211 [22].

A composição mineralógica do resíduo de ágata foi determinada por difração de raios-X, utilizando um difratômetro Rigaku modelo X-Ray, com voltagem de 40kVA e corrente de 40mA. A Figura 4 apresenta o difratograma obtido, caracterizando-o como um material de base silicosa e cristalino.

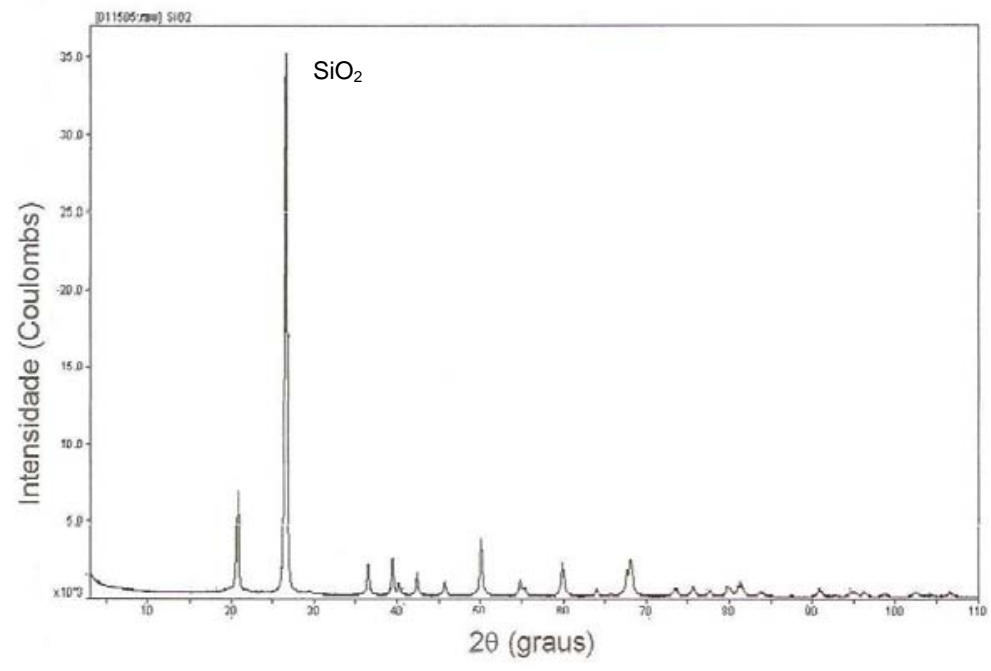

Figura 4: Difratograma do resíduo de ágata.

\subsection{3 Água}

A água utilizada na produção dos concretos foi proveniente da rede de água de abastecimento do município de Canoas/RS.

\subsection{Produção dos concretos}

Para a produção dos concretos foram realizadas quatro dosagens com os traços 1:3,5; 1:5,0 e 1:6,5, sendo a primeira somente com agregado natural (CREF) e as demais com os percentuais de agregado reciclado de ágata de 25\% (CRA25), 50\% (CRA50) e 75\% (CRA75). Os traços de concreto foram determinados com base no método de dosagem desenvolvido pelo IPT/EPUSP, descrito por Helene e Terzian [24], com um teor de argamassa de 53\%. Como parâmetro de controle foi estabelecido um abatimento pelo tronco de cone de $90 \pm 10 \mathrm{~mm}$, determinado conforme a NBR NM 67 [25].

Em função da diferença entre a massa específica dos agregados natural $\left(2,93 \mathrm{~kg} / \mathrm{dm}^{3}\right)$ e reciclado $\left(2,62 \mathrm{~kg} / \mathrm{dm}^{3}\right)$, realizou-se um ajuste na proporção de agregado reciclado, o que permitiu que fosse 
empregado o mesmo volume de agregado reciclado em relação ao volume de agregado natural para a produção do concreto, mantendo-se o mesmo teor de argamassa (em volume) para os concretos analisados.

Seguindo a recomendação da NBR 12655 [19], para cada mistura de concreto (12 traços) foram moldados dois corpos-de-prova (1 exemplar), totalizando 24 corpos-de-prova. Os corpos-de-prova cilíndricos, com 100mm de diâmetro de $200 \mathrm{~mm}$ de altura, foram moldados de acordo com as recomendações da NBR 5738 [26]. A cura dos corpos-de-prova foi realizada nas primeiras 24 horas em ambiente de laboratório. Após esse período, os corpos-de-prova foram desmoldados e armazenados em câmara úmida, com umidade relativa superior a $95 \%$ e temperatura de $(23 \pm 1)^{\circ} \mathrm{C}$ até a idade de 28 dias. A Tabela 6 apresenta os concretos utilizados no experimento.

Tabela 6: Concretos produzidos

\begin{tabular}{c|c|c|c|c|c}
\hline \multicolumn{2}{c|}{ Traço } & H\% & $\begin{array}{c}\text { Abatimento } \\
(\mathrm{mm})\end{array}$ & $\begin{array}{c}\text { C } \\
\left(\mathrm{kg} / \mathrm{m}^{3}\right)\end{array}$ & $\begin{array}{c}\text { Relação } \\
\mathrm{a} / \mathrm{c}\end{array}$ \\
\hline \multirow{3}{*}{ CREF } & $1: 3,5$ & 9,59 & 90 & 490 & 0,43 \\
& $1: 5,0$ & 9,02 & 100 & 371 & 0,54 \\
& $1: 6,5$ & 9,18 & 80 & 295 & 0,69 \\
\hline \multirow{3}{*}{ CRA25 } & $1: 3,5$ & 9,84 & 90 & 488 & 0,44 \\
& $1: 5,0$ & 9,42 & 95 & 369 & 0,56 \\
& $1: 6,5$ & 9,67 & 100 & 292 & 0,71 \\
\hline \multirow{3}{*}{ CRA50 } & $1: 3,5$ & 10,10 & 95 & 487 & 0,44 \\
& $1: 5,0$ & 9,26 & 80 & 371 & 0,54 \\
& $1: 6,5$ & 9,64 & 90 & 294 & 0,71 \\
\hline \multirow{5}{*}{ CRA75 } & $1: 3,5$ & 10,28 & 95 & 488 & 0,44 \\
& $1: 5,0$ & 9,53 & 90 & 369 & 0,55 \\
& $1: 6,5$ & 9,28 & 80 & 297 & 0,67 \\
\hline
\end{tabular}

\section{$2.4 \quad$ Método de ensaio}

O ensaio de resistência à compressão foi realizado segundo a NBR 5739 [27], aos 28 dias de idade, utilizando-se uma prensa EMIC com capacidade de 150 toneladas e velocidade de carregamento na faixa de 0,5 $\pm 0,2 \mathrm{MPa} / \mathrm{s}$. O capeamento dos corpos-de-prova foi realizado com mistura a base de enxofre.

\section{RESULTADOS E DISCUSSÃO}

A Tabela 7 apresenta os resultados obtidos no ensaio de resistência à compressão.

Tabela 7: Resultados de resistência à compressão (MPa)

\begin{tabular}{c|c|c|c}
\hline Traço & $1: 3,5$ & $1: 5,0$ & $1: 6,5$ \\
\hline \multirow{2}{*}{ CREF } & 34,6 & 28,1 & 17,4 \\
& 34,1 & 27,9 & 17,2 \\
\hline \multirow{2}{*}{ CRA25 } & 32,1 & 24,3 & 14,5 \\
\hline
\end{tabular}




\begin{tabular}{l|l|l|l}
\hline \multirow{2}{*}{ CRA50 } & 38,8 & 31,4 & 20,8 \\
& 38,5 & 31,0 & 20,6 \\
\hline \multirow{3}{*}{ CRA75 } & 33,1 & 28,4 & 20,4 \\
\hline
\end{tabular}

No presente trabalho foi priorizada a obtenção de um mesmo abatimento dos concretos preparados com as diferentes porcentagens de agregado reciclado, não sendo fixada a relação água/cimento. No entanto, tendo em vista a pequena variação da relação água/cimento observada em um mesmo traço com os diferentes teores de agregado reciclado, na Figura 5 apresentam-se os valores de resistência à compressão de forma comparativa, considerando o valor do exemplar, ou seja, o maior valor de resistência à compressão (valor potencial) de cada mistura produzida, conforme recomenda a NBR 12655 [19]. Observou-se que os concretos com 50\% de ágata apresentaram maior resistência à compressão, em todos os traços estudados.

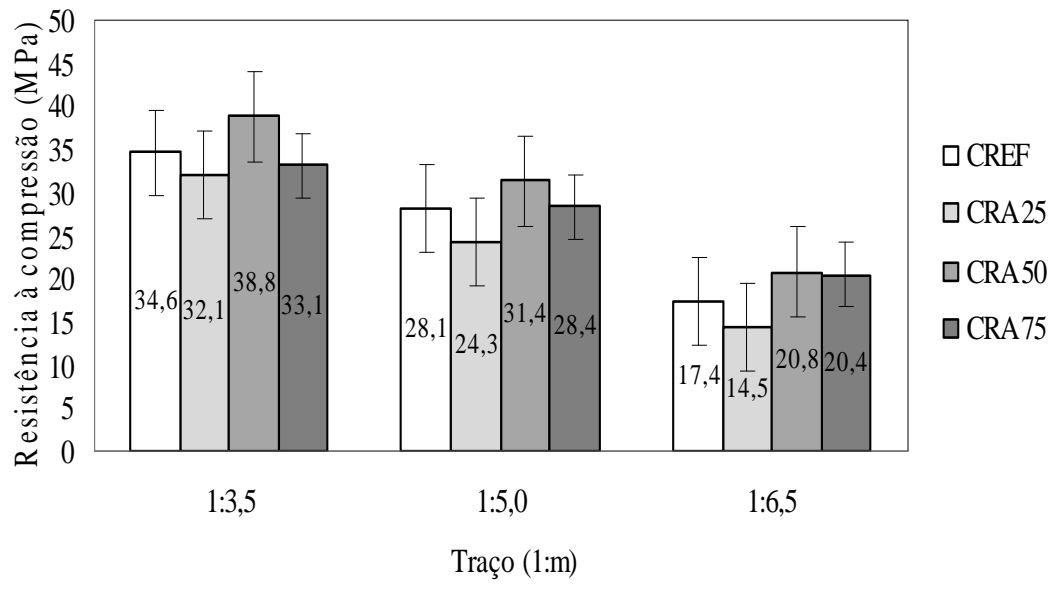

Figura 5: Resultados de resistência à compressão - 28 dias.

Os concretos com 50\% de resíduo de ágata, embora com maior relação água/cimento nos traços 1:3,5 e 1:6,5, apresentaram maior resistência à compressão em comparação aos demais concretos com resíduo e também ao concreto de referência, composto exclusivamente de agregado graúdo natural. Foi observado um aumento da resistência à compressão em relação ao concreto de referência de $12 \%$ para os traços 1:3,5 e 1:5,0 e 20\% para o traço 1:6,5.

A substituição de $75 \%$ de agregado natural por agregado reciclado de ágata pouco influenciou a resistência dos traços 1:3,5 e 1:5,0, proporcionando, no entanto, um aumento de 17\% para o traço 1:6,5. Os concretos com 25\% de ágata (CRA25) apresentaram menor resistência à compressão do que os concretos de referência, como pode ser observado na Figura 5.

O melhor desempenho dos concretos com 50\% de agregado reciclado pode ser atribuído a um melhor empacotamento dos grãos de agregado graúdo, favorecido pela composição granulométrica da mistura de agregados, a qual pode ter possibilitado uma menor quantidade de vazios, contribuindo para a maior resistência à compressão.

Segundo Mehta e Monteiro [28], as partículas de textura áspera, angulosas e alongadas requerem mais pasta de cimento do que partículas lisas e arredondadas para alcançar níveis de trabalhabilidade desejados. Tal afirmação aponta primeiramente um maior consumo de água no preparo dos concretos propostos, conforme o aumento do teor de ágata na mistura, pois o agregado de ágata apresenta características lamelares e angulosas além de textura áspera e rugosa. Sobre outro aspecto, o inverso, dado a particularidade do agregado de ágata de possuir superfícies polidas, resultado do processo de beneficiamento da rocha.

No presente estudo, conforme mostra a Tabela 5, o teor de água (H\%) exigido para o abatimento fixado, em geral, pouco aumentou com o percentual de agregado reciclado, não ocasionando alteração significativa na relação água/cimento. Esses resultados mostram que a morfologia da ágata não interferiu na trabalhabilidade do concreto como o esperado. Neville [29] ilustra tal situação afirmando que um agregado, mesmo com propriedades não satisfatórias em termos de morfologia deve ser sempre avaliado através das propriedades dos concretos produzidos com sua utilização. 
Com o objetivo de avaliar a significância das variáveis controláveis estudadas (traço de concreto e teor de agregado reciclado) na resistência à compressão foi realizada a análise estatística dos resultados através da análise de variância (ANOVA), considerando-se um nível de confiança de 95\%. A Tabela 8 apresenta a ANOVA para os resultados de resistência à compressão.

Tabela 8: Análise de variância para resistência à compressão

\begin{tabular}{c|c|c|c|c|c|c}
\hline Fonte & GDL & SQ & MQ & $F_{\text {calc. }}$ & "p-value” & Significância \\
\hline Fator A - Traço & 2 & 1090,82 & 545,41 & 9218,16 & 0,000 & Significativo \\
\hline $\begin{array}{c}\text { Fator B - Teor de } \\
\text { agregado de ágata }\end{array}$ & 3 & 135,63 & 45,21 & 764,13 & 0,000 & Significativo \\
\hline Interação AB & 6 & 18,30 & 3,05 & 51,59 & 0,000 & Significativo \\
\hline Erro & 12 & 0,72 & 0,06 & - & - & - \\
\hline
\end{tabular}

De acordo com os resultados da análise de variância (Tabela 8), os fatores traço (A) e teor de agregado reciclado (B), bem como a interação entre os dois fatores, são estatisticamente significativos na resistência à compressão em um nível de confiança de 95\%, visto que apresentam valores de "p-value" menor do que 0,05. A Figura 6 mostra a influência dos fatores analisados na resistência à compressão.

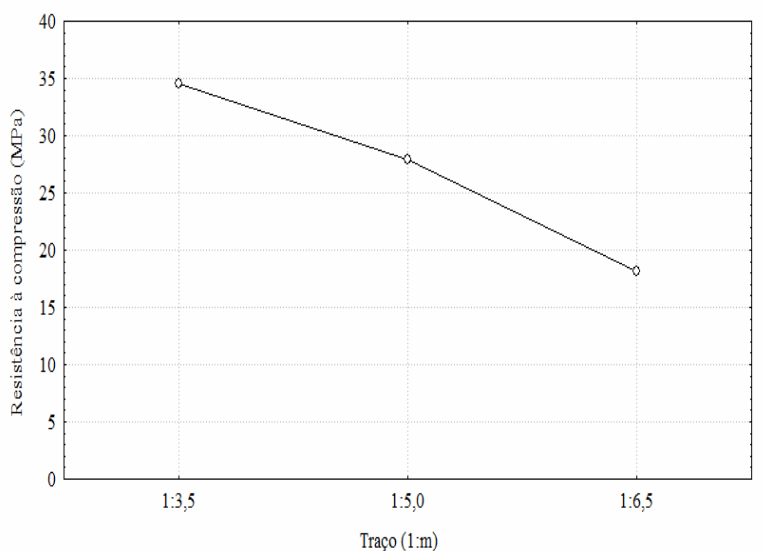

(a)

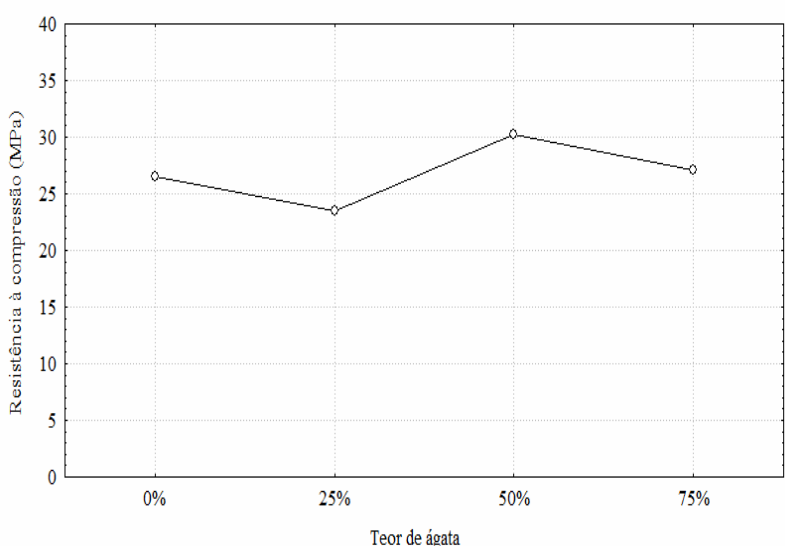

(b)

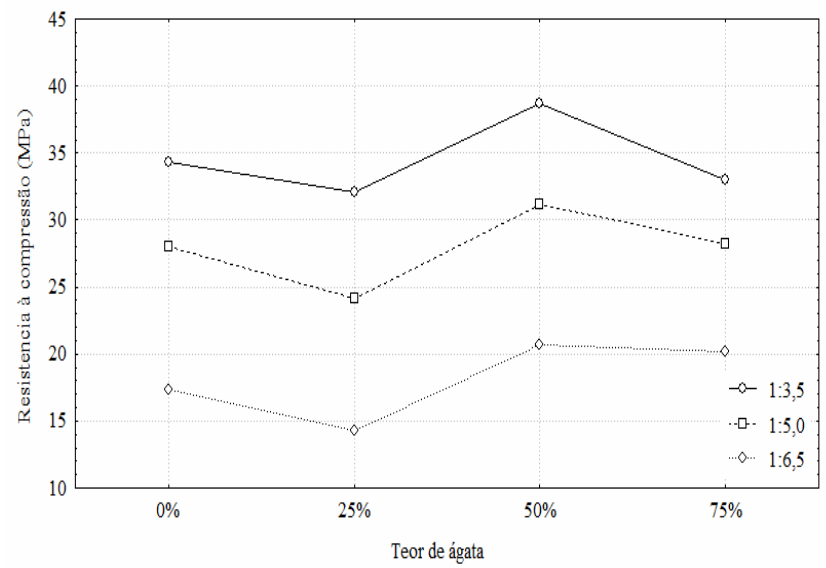

(c)

Figura 6: Efeito das variáveis (a) traço de concreto, (b) Teor de ágata e (c) interação entre traço e teor de ágata na resistência à compressão. 
Os resultados obtidos estão em conformidade com diversos estudos que avaliaram a possibilidade de incorporar agregados graúdos reciclados na produção de concreto demonstrando sua potencialidade de aplicação [1두 $\underline{30}, \underline{31}]$.

A partir dos resultados de resistência à compressão e dos parâmetros de produção das misturas foram obtidas curvas de Abrams para todos os traços estudados, conforme mostram os diagramas de dosagem apresentados nas Figuras 7 a 10.

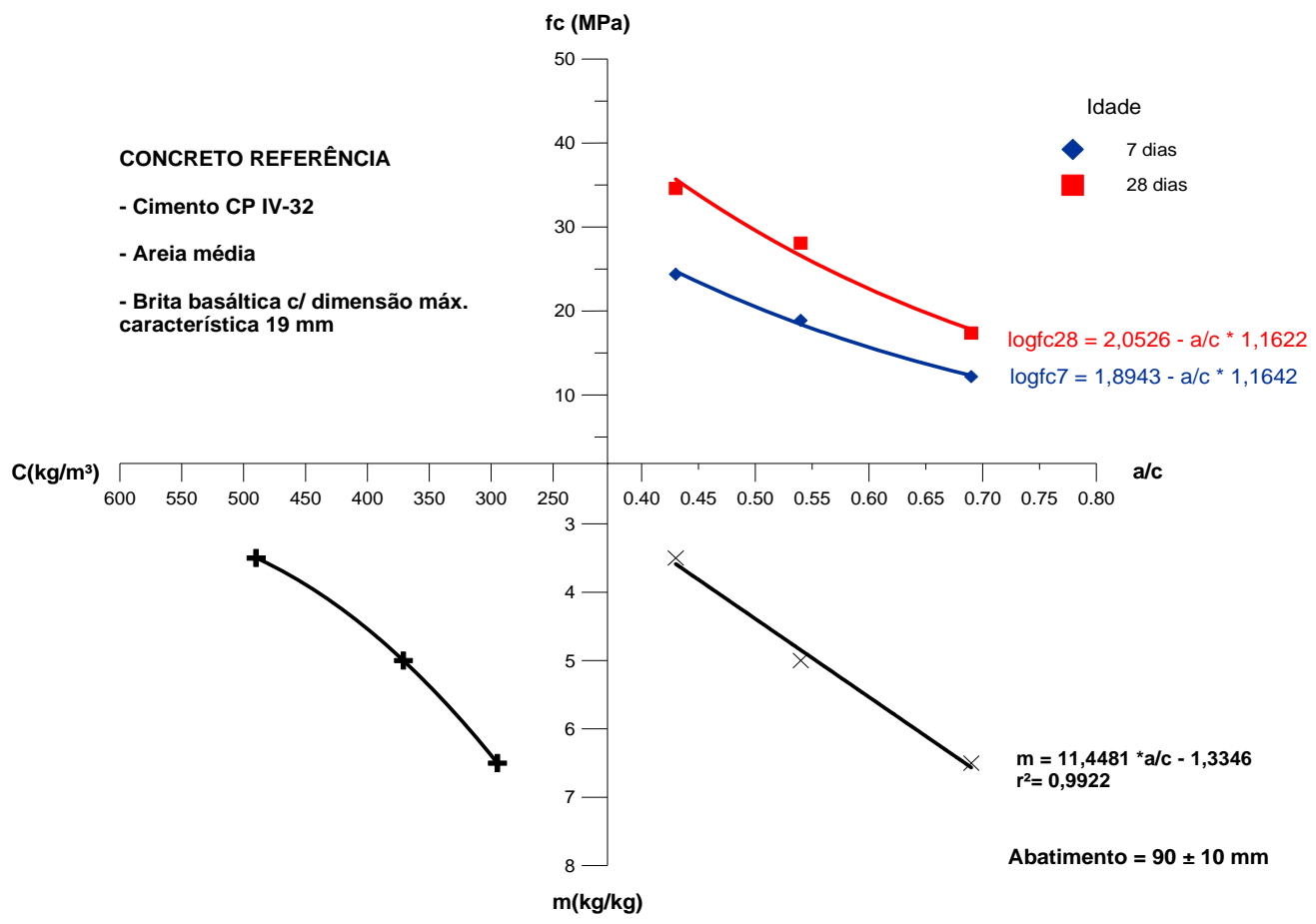

Figura 7: Diagrama de dosagem para o concreto de referência.

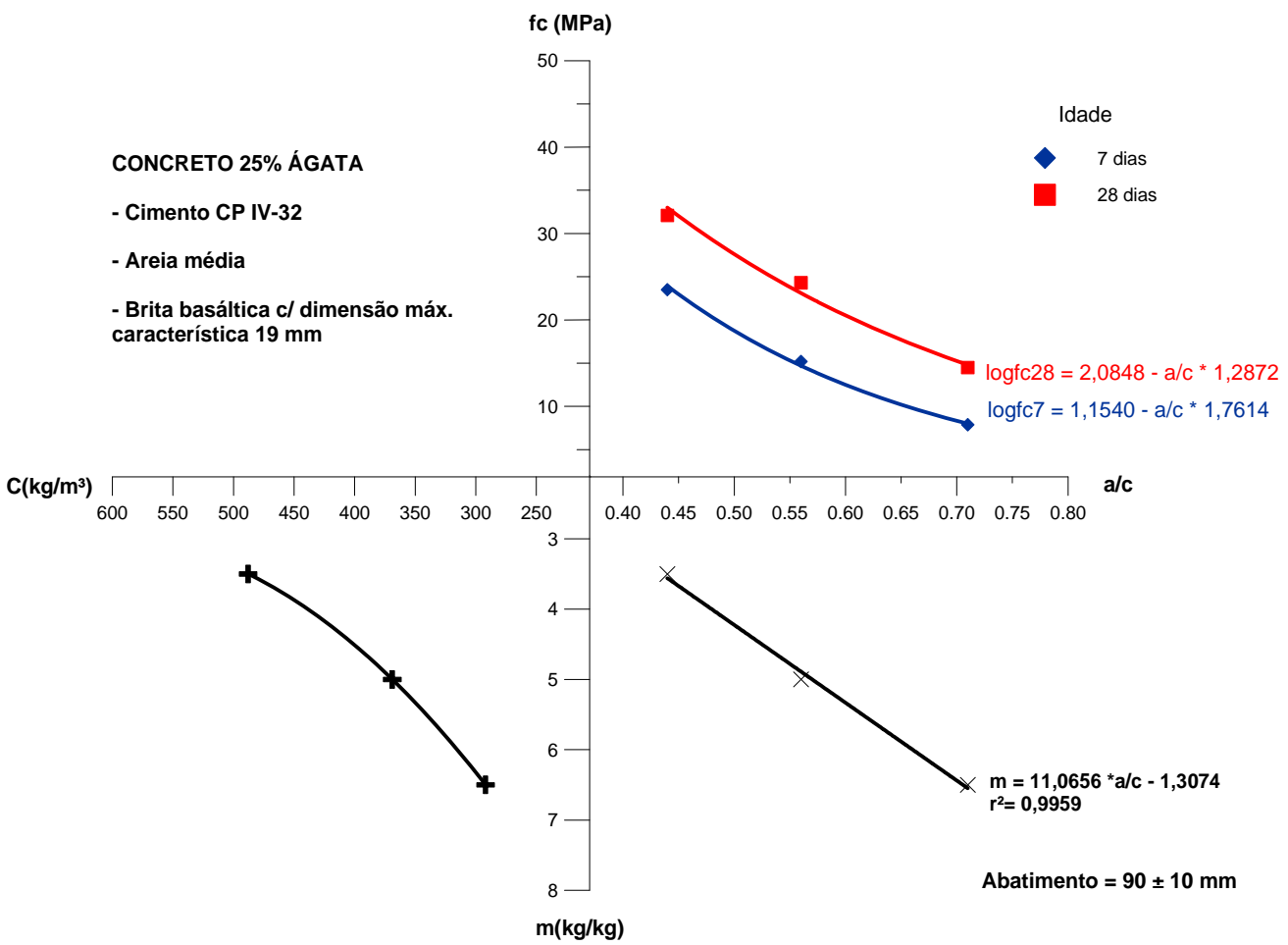

Figura 8: Diagrama de dosagem para o concreto com 25\% de agregado reciclado de ágata. 


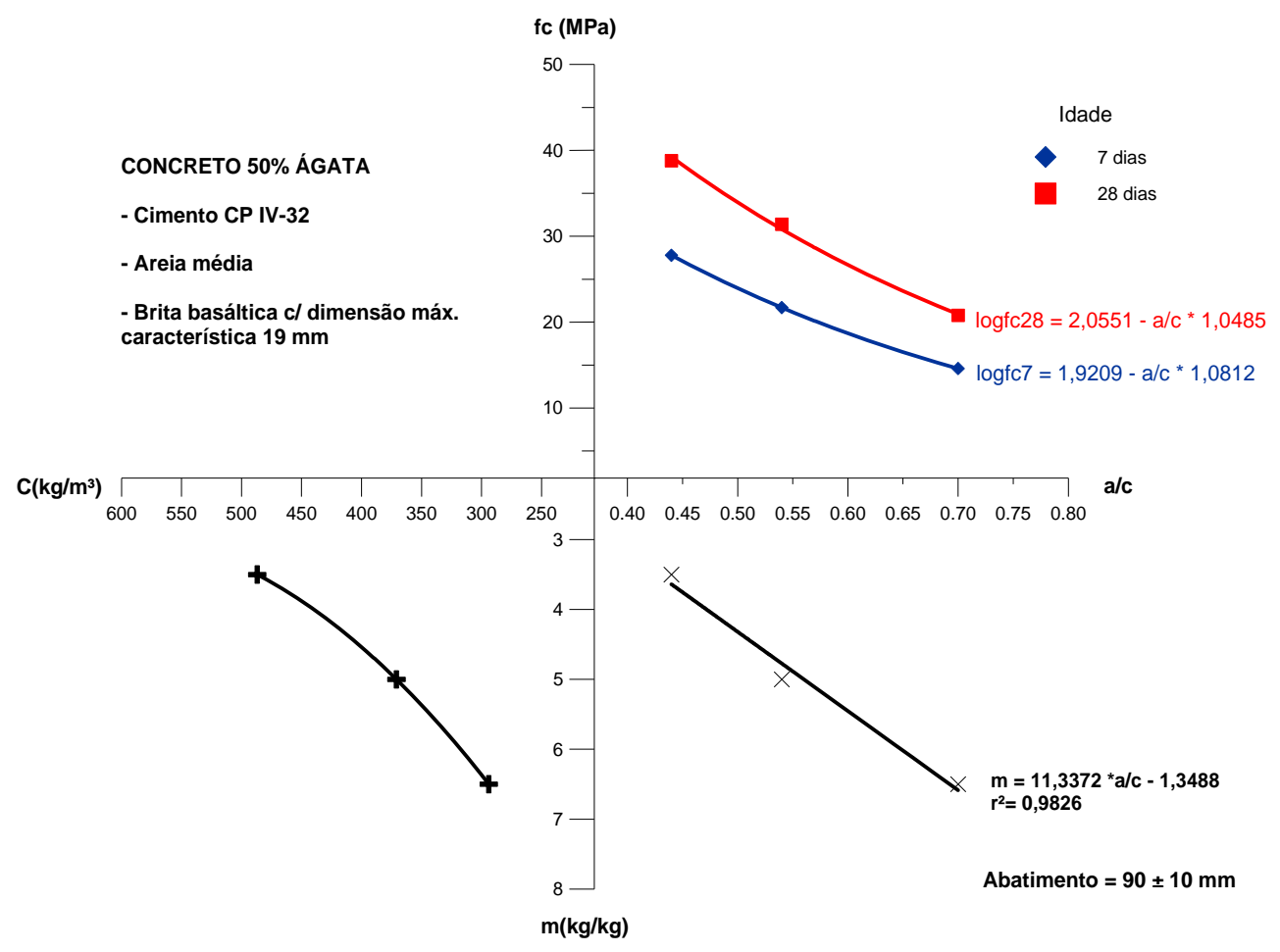

Figura 9: Diagrama de dosagem para o concreto com 50\% de agregado reciclado de ágata.

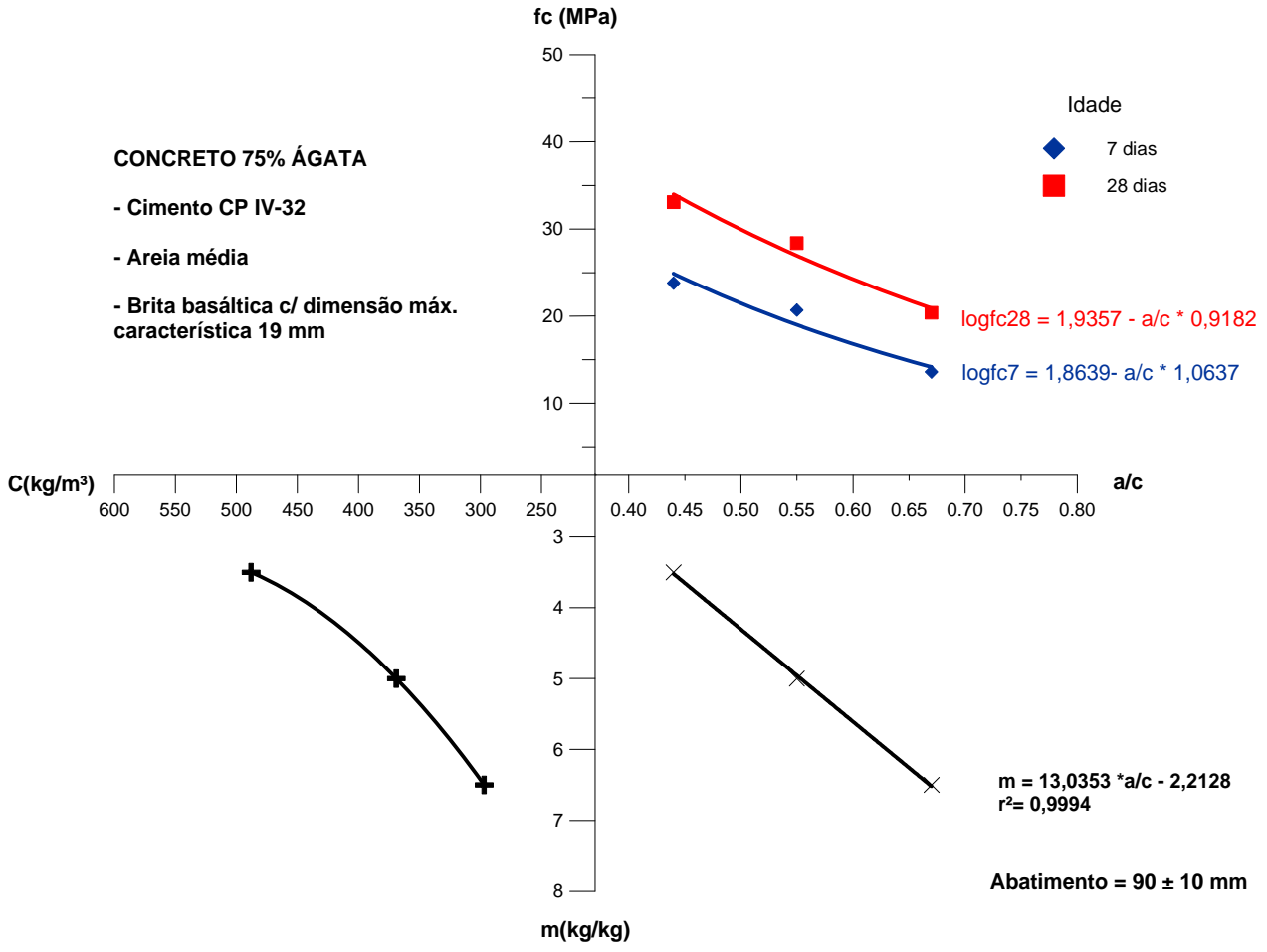

Figura 10: Diagrama de dosagem para o concreto com 75\% de agregado reciclado de ágata.

A partir dos diagramas de dosagem obtidos para cada concreto $(0,25,50$ e $75 \%$ de ágata) foram calculados traços de mesma resistência característica (fck), o que possibilitou a comparação do desempenho dos concretos através do consumo teórico de cimento em cada situação. As resistências características (fck) escolhidas para a avaliação do consumo de cimento foram $20 \mathrm{MPa}$, $25 \mathrm{MPa}$ e $30 \mathrm{MPa}$; considerando um 
desvio-padrão de dosagem de 4,0 MPa. A Figura 11 apresenta os consumos de cimento (C) para as resistências características analisadas.

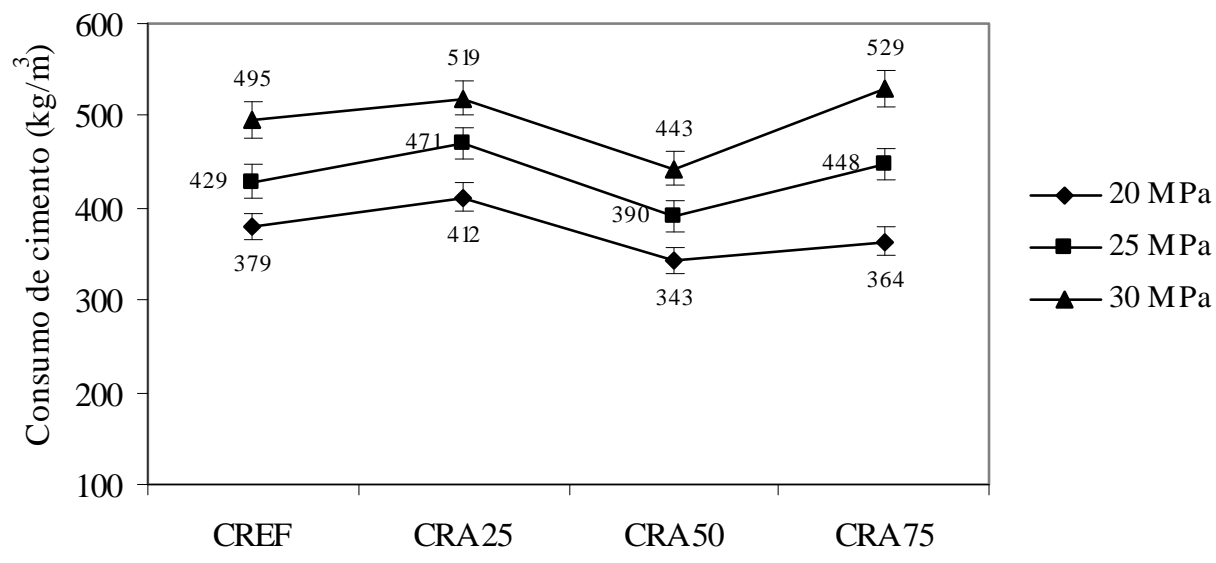

Concreto - teor de agregado reciclado

Figura 11: Consumo de cimento conforme a resistência característica.

Considerando os consumos de cimento determinados, observa-se que os concretos com $50 \%$ de ágata (CRA50) apresentaram menor consumo de cimento em relação ao concreto de referência, para todas as resistências características analisadas. A redução apresentada no consumo de cimento para o CRA50 foi de $10 \%$ em média.

Os concretos com $25 \%$ de ágata apresentaram consumos de cimento mais elevados que os concretos de referência, em média $8 \%$ maior.

A substituição de $75 \%$ de agregado natural por agregado reciclado acarretou menor consumo de cimento para a resistência característica de $20 \mathrm{MPa}$, com redução de $4 \%$. Já para as resistências características de 25 e $30 \mathrm{MPa}$ foi observado um maior consumo de cimento em relação ao concreto referência, da ordem de $4 \%$ e $7 \%$, respectivamente.

\section{CONCLUSÕES}

No presente trabalho foi avaliado o desempenho de concretos com substituição de 25 , 50 e $75 \%$ de agregado graúdo basáltico por agregado reciclado de ágata. Salienta-se que os resultados obtidos referem-se às condições específicas dos experimentos desenvolvidos, não devendo ser considerados de forma absoluta, sendo indicada a realização de pesquisas complementares para confirmar o desempenho dos agregados reciclados de ágata em concreto.

A partir da análise dos resultados obtidos foi possível concluir:

- A porcentagem de substituição de agregado reciclado utilizada para a produção dos concretos apresentou influência na resistência à compressão e no consumo de cimento;

- Os concretos com 50\% de substituição de agregado natural por agregado reciclado apresentaram resistência à compressão aproximadamente $10 \%$ maior do que os concretos de referência;

- A utilização do agregado reciclado de ágata pouco influenciou na demanda de água dos concretos produzidos;

- Os concretos CRA25 (25\% de ágata) apresentaram maior consumo de cimento para todas as resistências características avaliadas;

- Os concretos CRA50 (50\% de ágata) apresentaram menor consumo de cimento (em média $10 \%)$ para todas as resistências características avaliadas;

- Os concretos CRA75 (75\% de ágata) apresentaram menor consumo de cimento (4\%) para a resistência característica de $20 \mathrm{MPa}$ e maior consumo de cimento (de 4 a 6\%) para as resistências características de $25 \mathrm{MPa}$ e $30 \mathrm{MPa}$.

Os resultados apresentados indicam a potencialidade do aproveitamento dos resíduos de ágata na produção de concreto. Uma observação importante, no entanto, refere-se à necessidade de avaliação da reatividade potencial dos agregados obtidos de fragmentos de ágata, embora a difração de raios-X demonstre 
a natureza cristalina do resíduo. O fato de empregar cimento pozolânico do tipo CP IV, cujo teor de pozolana é admitido em até $50 \%$, para a confecção de concretos com agregados potencialmente reativos minimiza a possibilidade do desenvolvimento de reações deletérias do tipo álcali-agregado.

\section{AGRADECIMENTOS}

Os autores agradecem à Fundação de Ciência e Tecnologia do Estado do Rio Grande do Sul (CIENTEC) pelo apoio na realização do programa experimental.

\section{REFERÊNCIAS}

[1] VALLE, C.E., Qualidade Ambiental ISO 14000, SENAC, São Paulo, 2002.

[2] SECRETARIA DO MEIO AMBIENTE DE LAJEADO, Relatório Anual Meio Ambiente, Prefeitura Municipal de Lajeado, 2005.

[3] BETAT, E.F., Concretos produzidos com resíduos do beneficiamento de ágata: avaliação da resistência à compressão, Dissertação de Mestrado, PPGEAM/ULBRA, Canoas, RS, Brasil, 2006.

[4] JOHN, V.M., “Panorama sobre reciclagem de resíduos na construção civil”, In: 2 Seminário sobre Desenvolvimento Sustentável e Reciclagem na Construção Civil, São Paulo, 1999, Comitê Técnico CT 206 - Meio Ambiente - IBRACON, 1999.

[5] VALVERDE, F.M., Agregados para construção civil, Balanço Mineral Brasileiro, 2001.

[6] MOURA, W.A., Utilização de escória de cobre com adição e agregado miúdo para concreto, Tese de D. Sc., PPGEC/UFRGS, Porto Alegre, RS, Brasil, 2000.

[7] LEITE, M.B., Avaliação de propriedades mecânicas de concretos produzidos com agregados reciclados de resíduos de construção e demolição, Tese de D. Sc, PPGEC/UFRGS, Porto Alegre, RS, Brasil, 2001.

[8] LEVY, S.M., Contribuição ao estudo da durabilidade de concretos, produzidos com resíduos de concreto e alvenaria, Tese de Doutorado, EPUSP/USP, São Paulo, SP, Brasil, 2001.

[9] LOVATO, P.S., Verificação dos parâmetros de controle de agregados reciclados de resíduos de construção e demolição para utilização em concreto, Dissertação de M. Sc, PPGEC/UFRGS, Porto Alegre, RS, Brasil, 2007.

[10] RASHWAN, M.S., ABOURIZK, S., “The properties of recycled concrete”, Concrete International, v. 19, n. 7, pp. 56-60, July 1997.

[11] VIEIRA, G.L., Estudo do processo de corrosão sob a ação de íons cloreto em concretos obtidos a partir de agregados reciclados de resíduos de construção e demolição, Dissertação de M. Sc., PPGEC/UFRGS, Porto Alegre, RS, Brasil, 2003

[12] POON, C., CHAN, D., “The use of recycled aggregate in concrete in Hong Kong”, Resources, Conservation and Recycling, v. 50, pp. 293-305, 2007.

[13] GARLET, G., Aproveitamento de resíduos de E.V.A. como agregado para concreto leve na construção, Dissertação de M. Sc., PPGEC/UFRGS, Porto Alegre, RS, Brasil, 1998.

[14] BITTENCOURT, D., Estudo investigativo para a utilização de areias de fundição na confecção de concreto, Dissertação de M. Sc., PPGEAM/ULBRA, Canoas, RS, Brasil, 2006.

[15] SENTHAMARAI, R.M., MANOHARAN, P.D., “Concrete with ceramic waste aggregate”, Cement \& Concrete Composites, v. 27, pp. 910-913, 2005. 
[16] YANG, E., YI, S., LEEM, Y., "Effect of oyster shell substituted for fine aggregate on concrete characteristics: Part I. Fundamental properties”, Cement and Concrete Research, v. 35, pp. 21752182, 2005.

[17] CHOI, Y., MOON, D., CHUNG, J, CHO, S., "Effects of waste PET bottles aggregate on the properties of concrete”, Cement and Concrete Research, v. 35, pp. 776-781, 2005.

[18] MODRO, N.L.R., MODRO, N.R., MODRO, N.R'., OLIVEIRA, A.P.N., “Avaliação de concreto de cimento Portland contendo resíduos de PET”, Revista Matéria, v. 14, n. 1, pp. 725-736, 2009.

[19] ASSOCIAÇÃO BRASILEIRA DE NORMAS TÉCNICAS, NBR 12655: Concreto - Preparo, controle e recebimento, Rio de Janeiro, 2006.

[20] _ _ NBR NM 248: Agregados - Determinação da composição granulométrica, Rio de Janeiro, 2003.

[21] _ _ NBR NM 52: Agregado miúdo - Determinação da massa específica e massa específica aparente. Rio de Janeiro, 2003.

[22] _ _ NBR 7211: Agregados para concreto - Especificação, Rio de Janeiro, 2006.

[23] _ _ NBR 7809: Agregado graúdo - Determinação do índice de forma pelo método do paquímetro, Rio de Janeiro, 1993.

[24] HELENE, P. e TERZIAN, P., Manual de dosagem e controle do concreto, Brasília, 1 ed., Pini, 1992.

[25] ASSOCIAÇÃO BRASILEIRA DE NORMAS TÉCNICA, NBR NM 67: Concreto - Determinação da consistência pelo abatimento do tronco de cone, Rio de Janeiro, 1998.

[26] _ _ NBR 5738: Concreto - Moldagem e cura de corpos-de-prova cilíndricos ou prismáticos de. Concreto, Rio de Janeiro, 1994.

[27] _ NBR 5739: Concreto - Ensaio de compressão de corpos-de-prova cilíndricos, Rio de Janeiro, 1994.

[28] MEHTA, P. K., MONTEIRO, P.J.M., Concreto: estrutura, propriedades e materiais, 1 ed., São Paulo, Pini, 1994.

[29] NEVILLE, A.M., Propriedades do concreto, 2 ed., São Paulo, Pini, 1997.

[30] DEBIED, F., KENAI, S., "The use of coarse and fine crushed bricks as aggregate in concrete", Construction and Building Materials, v. 22, pp. 886-893, 2008.

[31] BINICI, H., SHAH, T., AKSOGAN, O., KAPLAN, H., "Durability of concrete made with granite and marble as recycle aggregates”, Journal of Materials Processing Technology, Article in press. 